\title{
Aging-Related Increases in Behavioral Variability: Relations to Losses of Dopamine $\mathrm{D}_{1}$ Receptors
}

\author{
Stuart W. S. MacDonald, ${ }^{1}$ Sari Karlsson, ${ }^{2}$ Anna Rieckmann, ${ }^{2}$ Lars Nyberg ${ }^{3,4}$ and Lars Bäckman, $\mathrm{PhD}^{2}$ \\ ${ }^{1}$ Department of Psychology, University of Victoria, Victoria, British Columbia, Canada V8W 3P5, ${ }^{2}$ Aging Research Center, Karolinska Institute, S-113 30 \\ Stockholm, Sweden, and Departments of ${ }^{3}$ Integrative Medical Biology and ${ }^{4}$ Radiation Sciences, Umeå University, SE-901 87 Umeå, Sweden
}

Intraindividual variability (IIV) reflects within-person changes in performance, such as trial-by-trial fluctuations on a reaction-time (RT) task. The neural underpinnings of IIV remain largely unknown. The neurotransmitter dopamine (DA) is of particular interest here, as human populations that exhibit DA alterations, such as the elderly, attention deficit hyperactivity disorder children, persons with schizophrenia, and Parkinson patients, also show increased behavioral IIV. We examined links between DA $\mathrm{D}_{1}$ binding potential (BP) in multiple brain regions and IIV for the control and interference conditions of the Multi-Source Interference Task (MSIT), tapping the cingulo-fronto-parietal attention network. Participants were 18 young and 20 healthy old adults. PET and the radioligand [ $\left.{ }^{11} \mathrm{C}\right] \mathrm{SCH} 23390$ were used to determine $\mathrm{D}_{1} \mathrm{BP}$. The intraindividual standard deviation (ISD) was computed across successful latency trials of the MSIT conditions, independent of mean RT differences due to age, trial, and condition. Increasing ISDs were associated with increasing age and diminished $\mathrm{D}_{1}$ binding in several brain regions (anterior cingulate gyrus, dorsolateral prefrontal cortex, and parietal cortex) for the interference, but not control, condition. Analyses of partial associations indicate that the association between age and IIV in the interference condition was linked to $\mathrm{D}_{1}$ receptor losses in task-relevant brain regions. These findings suggest that dysfunctional DA modulation may contribute to increased variability in cognitive performance among older adults.

\section{Introduction}

Intra-individual variability (IIV) in cognitive performance increases in old age (Lövdén et al., 2007; MacDonald et al., 2009). For example, in reaction-time (RT) tasks, older adults are routinely more variable from trial to trial than their younger counterparts (Hultsch et al., 2002; West et al., 2002). These increases in variability have been linked to deleterious outcomes, including cognitive impairment, dementia, and death (e.g., MacDonald et al., 2008 , 2009). Importantly, age-related increases in IIV are independent of differences between young and old adults in mean latencies (Strauss et al., 2002; Hultsch et al., 2007). Numerous researchers have noted that theoretically interesting aspects of cognitive function may not be captured by measures of central tendency (e.g., Spieler et al., 2000; Ratcliff et al., 2004). Two distributions may exhibit similar central tendency estimates but have distributions and associated variance estimates that differ significantly.

Structural (Bunce et al., 2007) and functional (Kelly et al., 2008) brain alterations have been linked to increased IIV in

\footnotetext{
Received Oct. 29, 2011; revised March 26, 2012; accepted April 25, 2012.

Author contributions: S.W.S.M., L.N., and L.B. designed research; S.W.S.M. performed research; S.W.S.M. and S.K. analyzed data; S.W.S.M., S.K., A.R., and L.B. wrote the paper.

This research was supported by grants from the Swedish Research Council to L.B. and L.N., Swedish Brain Power, an Alexander von Humboldt Research Award, and a donation from the AF Jochnick Foundation to L.B., and the Joint Committee for Nordic Research Councils in the Humanities and the Social Sciences for a Nordic Center of Excellence to L.N. S.M. was supported by a Scholar Award from the Michael Smith Foundation for Health Research. S.K. was supported by grants from the Royal Swedish Academy of Sciences and the Gamla Tjänarinnor Foundation.

The authors declare no competing financial interests.

Correspondence should be addressed to Stuart W. S. MacDonald, Department of Psychology, University of Victoria, P0 Box 3050 STN CSC, Victoria, British Columbia, Canada V8W 3P5. E-mail: smacd@uvic.ca.

DOI:10.1523/JNEUROSCI.5474-11.2012

Copyright $\odot 2012$ the authors $\quad 0270-6474 / 12 / 328186-06 \$ 15.00 / 0$
}

advanced age. Another potential biological mechanism underlying age-related increases in IIV is impaired dopamine (DA) functions. There are marked DA losses in aging (Bäckman et al., 2006; 2010), and many other conditions associated with increased IIV (e.g., attention deficit hyperactivity disorder, Parkinson's disease, schizophrenia) are characterized by deficient dopaminergic neuromodulation (MacDonald et al., 2006; 2009). Further, DA losses have been linked to increased neural noise, which in turn has been associated with increased IIV (Cohen and Servan-Schreiber, 1992; Li et al., 2001; Bäckman et al., 2010).

Despite the biological plausibility of a relationship among aging, DA, and IIV, no direct empirical evidence to substantiate this link is available. Using PET and the radioligand $\left[{ }^{11} \mathrm{C}\right] \mathrm{SCH} 23390$, we sought to provide such evidence by assessing $\mathrm{DA}_{1}$ receptor densities in young and old adults while performing the MultiSource Interference Task (MSIT), which taxes interference resolution (Bush et al., 2003).

Functional magnetic resonance imaging (fMRI) research indicates that BOLD activity in a cingulo-fronto-parietal (CFP) network, including anterior cingulate cortex (ACC), dorsolateral prefrontal cortex (DLPFC), and parietal cortex (PC), is implicated in interference resolution in the MSIT (Bush et al., 2003; Bush and Shin, 2006). Given links between DA signaling and BOLD activity (Schott et al., 2008; Landau et al., 2009; Nyberg et al., 2009; Bäckman et al., 2011a,b), these regions were targeted in determining age-related differences in $\mathrm{D}_{1}$ binding potential (BP). The caudate was used as a control region, as this is a structure in which DA innervation is particularly dense (Bäckman et al., 2006; 2010). 


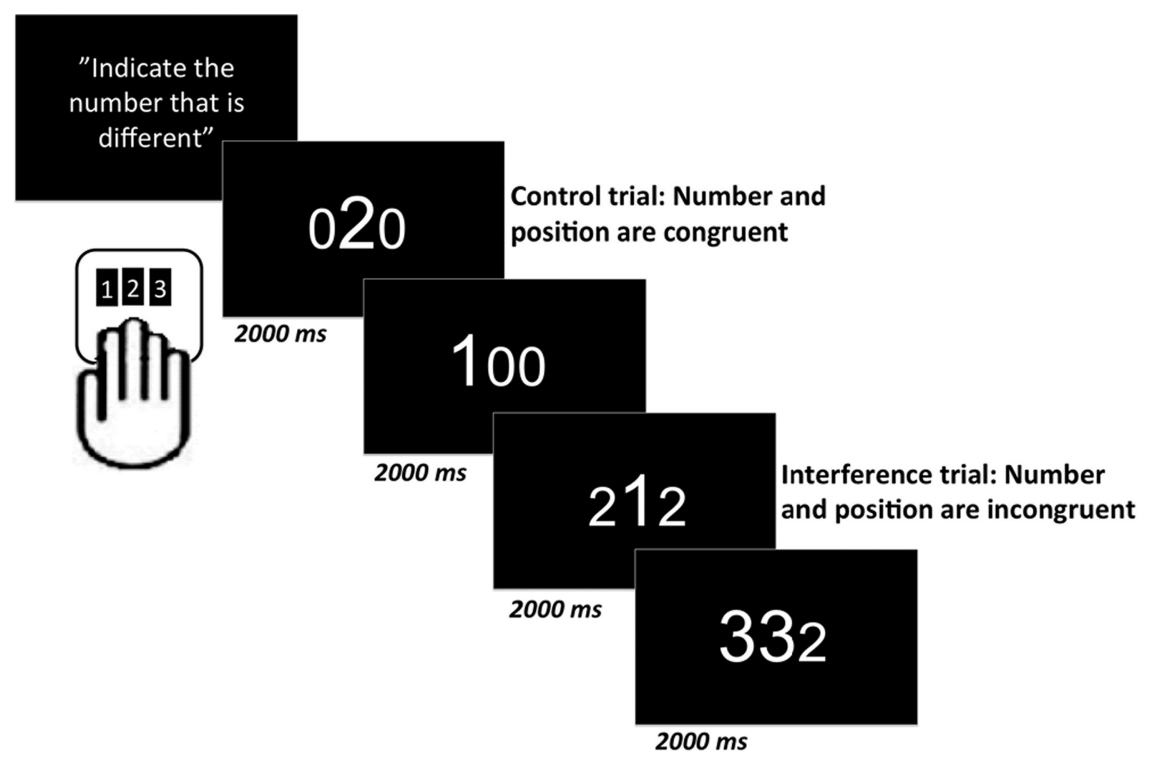

Figure 1. During performance on the Multi Source Interference task, participants are instructed to identify a digit that is different from two other digits, as quickly and accurately as possible. Upon determining the unique target number, participants pressed the button corresponding to the correct response (the spatial location of the correct number) on a keypad with three buttons.

The chief objective of this investigation was to determine the role of losses of $D_{1}$ receptors for age-related increases in IIV. Specifically, we examined whether the link between aging and IIV would be related to $\mathrm{D}_{1} \mathrm{BP}$ for regions implicated in previous fMRI work on the MSIT.

\section{Materials and Methods}

Participants. Twenty young and twenty old persons were recruited through a newspaper advertisement. One young female subject had missing data on the MSIT, due to problems with the response pad, and one young female had an error rate of over 95\%; these individuals were excluded from subsequent analysis. The final sample consisted of 18 young (mean age $=25.28$ years, range $=22-0 ; 10$ male, 8 female) and 20 old (mean age $=70.35$ years, range $=65-5 ; 10$ male, 10 female $)$ participants. Mean years of education were 14.39 for the young $(\mathrm{SD}=1.86)$ and 14.30 for the old $(\mathrm{SD}=3.96, p=0.89)$. Exclusion criteria included mental disorders, brain damage, other significant medical conditions, actual or previous drug or alcohol abuse, and nicotine use, as well as women receiving hormone replacement therapy. Cognitive testing outside the PET system revealed that the two samples were highly representative of their birth cohorts. There was a clear advantage of the young for tests of episodic memory and perceptual speed (M, mean) (Free Recall of Words: $\mathrm{M}_{\text {young }}=11.78[\mathrm{SD}=2.39], \mathrm{M}_{\text {old }}=9.60[\mathrm{SD}=2.46], t=2.76$, $p<0.01$; Digit Symbol: $\mathrm{M}_{\text {young }}=35.33[\mathrm{SD}=14.51], \mathrm{M}_{\mathrm{old}}=20.30$ $[\mathrm{SD}=5.90], t=4.10, p<0.01)$. By contrast, the old outperformed the young in tests of crystallized intelligence (Vocabulary: $\mathrm{M}_{\text {young }}=29.39[\mathrm{SD}=$ $2.62], \mathrm{M}_{\text {old }}=33.30[\mathrm{SD}=2.00], t=-5.21, p<0.01$; General Knowledge: $\mathrm{M}_{\text {young }}=23.06[\mathrm{SD}=2.31], \mathrm{M}_{\text {old }}=25.30[\mathrm{SD}=3.08], t=-2.52, p=$ $0.02)$. Written informed consent was obtained from all participants, with the study approved by the Ethics and Radiation Safety Committees of the Karolinska Hospital, Stockholm, Sweden. Participants were paid 5000 SEK for their participation.

Cognitive assessment. The MSIT is an interference task involving a combination of Stroop, Flanker, and Simon-type tasks (Bush et al., 2003). Participants were shown a series of stimulus arrays comprised of three numbers in a horizontal line. For each three-number array, participants were to indicate, as quickly and accurately as possible, which individual number (the "target") differed from the other two (the "distracters"; see Fig. 1). Upon determining the unique target number (e.g., " 1 " in the array " 100 ", participants pressed the button corresponding to the correct response (the spatial location of the correct num- ber) on a keypad with three buttons representing the numbers 1,2 , and 3 from left to right. The task included 384 control trials and 384 interference trials. In the control trials, the distracters were always zeroes ( 0 ), the font size of the target was always larger than the distracters, and the target was always presented congruently or spatially mapped with the button press position (e.g., $020 ; 100$ ). For the interference trials, both the target and distracters were nonzero values, the font size of the target number could be larger or smaller than the distracters, and the spatial location of the target was always presented incongruently with the button press position representing the correct response (e.g., $313 ; 22$ 1). Trials were presented in 16 blocks with 24 control trials and 24 interference trials in each block. Each trial lasted $2 \mathrm{~s}$. After blocks four and eight, there was a $90 \mathrm{~s}$ break. The cognitive task started simultaneously with the PET measurement and lasted for $\sim 30 \mathrm{~min}$. Accuracy and response latencies were calculated separately for control versus interference trials.

Intraindividual standard deviation. Intraindividual variability was indexed as intraindividual standard deviations (ISDs; Hultsch et al., 2007) across correct response latency trials of the control and interference conditions of the MSIT. Consistent with the approach advocated by Hultsch et al. (2007), mean age group differences in response latency as well as learning effects across trials were partialled before computing ISDs. As a consequence, associations between DA binding and ISDs will not be an artifact of age differences in mean response latency or individual differences in learning. To facilitate interpretation, ISDs were scaled as $T$ scores $(\mathrm{M}=50$; $\mathrm{SD}=10)$.

Positron emission tomography and magnetic resonance imaging. PET measurements were obtained with an ECAT Exact HR 47 system (CTI/ Siemens) run in 3D mode and with a transaxial resolution of $3.8 \mathrm{~mm}$ full width at half maximum at the central field of view and $4.5 \mathrm{~mm}$ radially at $20 \mathrm{~cm}$ from the center. Following a transmission measurement of $10 \mathrm{~min}$ with three rotating $68 \mathrm{Ge}-68 \mathrm{Ga}$ sources, $300 \mathrm{MBq}$ of $\left[{ }^{11} \mathrm{C}\right] \mathrm{SCH} 23390$ (Halldin et al., 1986) was injected into the left antecubital vein as a rapid bolus injection. Emission data were recorded over a period of $51 \mathrm{~min}$ in 13 time frames of increasing duration. A T1-weighted magnetic resonance image (MRI) with a voxel size of $1.02 \times 1.02 \times 1.00 \mathrm{~mm}$ was acquired on a 1.5 T GE Signa Scanner and coregistered to the summated PET image. The anatomical MRI was then segmented into gray matter, white matter, and CSF, and the segmented gray matter regions of interest (ROIs) were used to obtain time activity curves (TACs) from the PET images for each hemisphere. For all analyses, DA BP estimates were collapsed across hemispheres, justified by high interhemispheric correlations ( $p s<0.05$ ). The MSIT task was performed during PET acquisition. Cognitive task performance has been shown to affect BP estimates of $D_{2}$ receptor ligands because of displacement of the ligand with endogenous DA (e.g., Koepp et al., 1998; Schott et al., 2008). However, there is little evidence for displacement of SCH23390 following pharmacological challenges (Abi-Dargham et al., 1999; Chou et al., 1999), making it unlikely that BP estimates in the current sample were confounded by task-evoked DA release.

For TAC generation, radioactivity was plotted versus time and corrected for decay. $\mathrm{D}_{1}$ receptor density was measured as the $\mathrm{BP}$ of $\left[{ }^{11} \mathrm{C}\right] \mathrm{SCH} 23390$, defined as the ratio at equilibrium of specifically bound radioligand to that of nondisplaceable radioligand in tissue (Innis et al., 2007) and calculated using the simplified reference tissue model (Lammertsma and Hume, 1996). PET data were corrected for partialvolume effects (Meltzer et al. 1990). There were no age-related differences in the general shape or time of peak of the TACs.

Regions of interest. ROIs were manually delineated on each individual's coregistered MR image using the Human Brain Atlas software (Roland et 

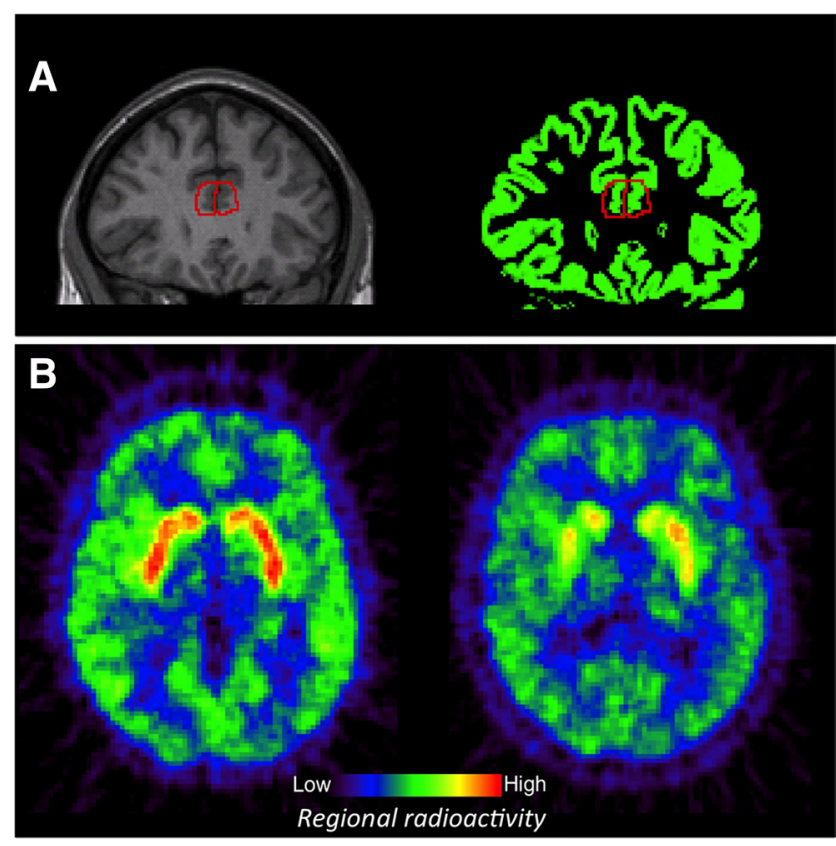

Figure 2. Regions of interest for derivation of regional binding potentials were manually delineated on MRI images $(\boldsymbol{A}$, left). Only segmented gray matter portions of the delineated regions were used in PET analyses ( $\boldsymbol{A}$, right). $\boldsymbol{B}$ gives an example of two PET images showing regional radioactivity in a young person on the left and an old person on the right.

al., 1994; Fig. 2A). Based on past fMRI work identifying brain regions implicated in interference resolution (Bush et al., 2003; Bush and Shin, 2006), we delineated ACC, DLPFC, and PC; the caudate was delineated as a control region.

Boundaries for all ROIs were based on previously published reports (Abi-Dargham et al., 2002; Cervenka et al. 2008, 2010) and an MRI-based atlas (Tamraz and Comair, 2005). For each hemisphere, DLPFC was delineated as the medial-inferior and lateral part of superior frontal gyrus, the ACC as the anterior part of the cingulate gyrus, inferior to the cingulate sulcus and superior to corpus callosum, and the PC posteriorly bounded by the parieto-occipital sulcus, inferiorly by the cingulate sulcus, and anteriorly by the central sulcus. The cerebellum, where dopamine $\mathrm{D}_{1}$ receptor density is negligible, served as reference region (Hall et al., 1988). The ROIs were manually delineated on each individual MR image using the Human Brain Atlas software (Roland et al., 1994). The PET images were coregistered to the MR images and resliced to a voxel size of $2 \times 2 \times 2 \mathrm{~mm}$. The MRI-defined ROIs were displayed on the corresponding PET images (Fig. $2 B$ ).

Statistical analysis. Differences as a function of MSIT condition (control vs interference) and age group (young vs old) were examined with repeated-measures ANOVAs. Mean $\mathrm{D}_{1} \mathrm{BP}$ as a function of ROI and age group were examined with ANOVA. Multiple regression was used to examine the associations between performance on the MSIT, $\mathrm{D}_{1} \mathrm{BP}$ for key ROIs and age, as well as the age $\times D_{1}$ BP interactions. A final set of analyses used multiple regression to compare the direct effects of age on MSIT performance before and following the inclusion of $\mathrm{DA} \mathrm{D}_{1}$ binding for each ROI in the model.

\section{Results}

Both young and old adults performed at a very high level on the MSIT (accuracy $>90 \%$ ). There was no age difference on control item accuracy (young $=99.3 \%$; old $=99.0 \%$ ), although there was an advantage for the young on interference item accuracy (young $=96.2 \%$; old $=90.2 \%, p<0.05$ ). There were significant age group differences for response latency $(\mathrm{RT}), F_{(1,36)}=9.33$, $p<0.01, \eta^{2}=0.21$, and variability (ISD), $F_{(1,36)}=4.97, p<0.05$, $\eta^{2}=0.12$. The younger group responded significantly faster and exhibited less variability than the older group. Significant effects
Table 1. Dopamine $D 1$ binding potential across age and brain region

\begin{tabular}{lllll}
\hline Brain region & Young & Old & \% Age difference & $p$ \\
\hline Caudate & 1.66 & 1.41 & 15 & $<0.01$ \\
DLPFC & 0.50 & 0.40 & 20 & $<0.01$ \\
ACC & 0.51 & 0.38 & 25 & $<0.01$ \\
PC & 0.50 & 0.41 & 18 & $<0.01$ \\
\hline
\end{tabular}

DLPFC, Dorsolateral prefrontal cortex; $A C C$, anterior cingulate cortex; $P C$, parietal cortex; \% Age difference reflects the proportional age-related loss in binding potential for each region of interest; $p$ refers to significance level of the corresponding $t$ statistic between age groups.

were also observed for mean RT and ISD as a function of MSIT condition (control vs interference; mean RT: $F_{(1,36)}=739.94$, $p<0.01, \eta^{2}=0.95$; ISD: $\left.F_{(1,36)}=77.52, p<0.01, \eta^{2}=0.68\right)$, as well as for the Age $\times$ MSIT condition interaction (mean RT: $F_{(1,36)}=4.51, p<0.05, \eta^{2}=.11$; ISD: $F_{(1,36)}=6.56, p<0.05$, $\left.\eta^{2}=0.15\right)$. The interaction reflected no significant age differences for the control condition, but significantly slower and more variable responses for the older group in the interference condition.

Before examining the influence of DA BP on the association between age and MSIT performance, we quantified the agespecific BPs for the ROIs. Table 1 plots regional $\mathrm{D}_{1} \mathrm{BP}$ by age group, including the proportional age-related BP loss for each region and associated statistical comparisons between age groups. As is evident from the table, the age-related downregulation of $\mathrm{D}_{1} \mathrm{BP}$ is relatively constant across regions.

Figure 3 displays the associations between $\mathrm{D}_{1} \mathrm{BP}$ for the ROIs with variability and mean response latency for the MSIT interference condition. Across all individuals, associations were observed between response latency and variability in the interference condition and BP for DLPFC, ACC, and PC, but not for the caudate. Figure 3 also displays the links between MSIT performance and $\mathrm{D}_{1} \mathrm{BP}$ within age groups. The regression of the cognitive variables on $\mathrm{D}_{1} \mathrm{BP}$ and age yielded a significant $\mathrm{Age}^{\star} \mathrm{BP}$ interaction $\left(p_{\mathrm{Age}^{\star} \mathrm{ACC}}<0.05\right.$ one-tailed) for the ACC; increased variability on the MSIT interference condition was linked to diminished $D_{1}$ BP for ACC in the old (but not young) age group. No significant interactions were observed for the other ROIs, indicating that associations between BP and cognitive variables did not differ between age groups (ISD: $p_{\mathrm{Age}^{*} \mathrm{DLPFC}}>0.35, p_{\mathrm{Age}^{*} \mathrm{PC}}>0.05$, $p_{\text {Age }{ }^{*} \text { Caudate }}>0.40$; mean RT: $p_{\text {Age }^{*} \text { DLPFC }}>0.20, p_{\text {Age }^{*} \text { ACC }}>0.35$, $\left.p_{\text {Age }{ }^{*} \text { PC }}>0.35, p_{\text {Age }^{*} \text { Caudate }}>0.35\right)$. Notably, the magnitude of the associations in the interference condition was somewhat greater for age-partialed measures of variability compared with mean latency, particularly for the old. However, these differences were not significant ( $p s>0.10$, one-tailed) based on a procedure for comparing coefficients from dependent samples with overlapping variables (Cohen and Cohen, 1983). There were no significant relationships of $D_{1} B P$ and response latency or variability for the control condition for the entire sample $(p s>0.10$, onetailed) or within age groups ( $p s>0.05$, one-tailed).

A final set of analyses evaluated to what extent $\mathrm{DA} \mathrm{D}_{1}$ binding modulated the association of age to RT and variability scores. The direct effect of age on response latency and variability, respectively, for the MSIT interference condition was $r=0.47$ and $r=$ $0.43(p<0.01$, one-tailed).

To evaluate the indirect effects, $D_{1}$ binding for each ROI was introduced as a mediator of the age-MSIT associations. The significance of the indirect effects from age through $\mathrm{D}_{1}$ BP to MSIT performance was obtained by computing bootstrapped $90 \%$ confidence intervals in AMOS 19. For mean RT in MSIT-interference performance, the magnitude and significance (one-tailed) of indirect effects was $0.002(p>0.48)$ for caudate, $0.04(p>0.35)$ for 

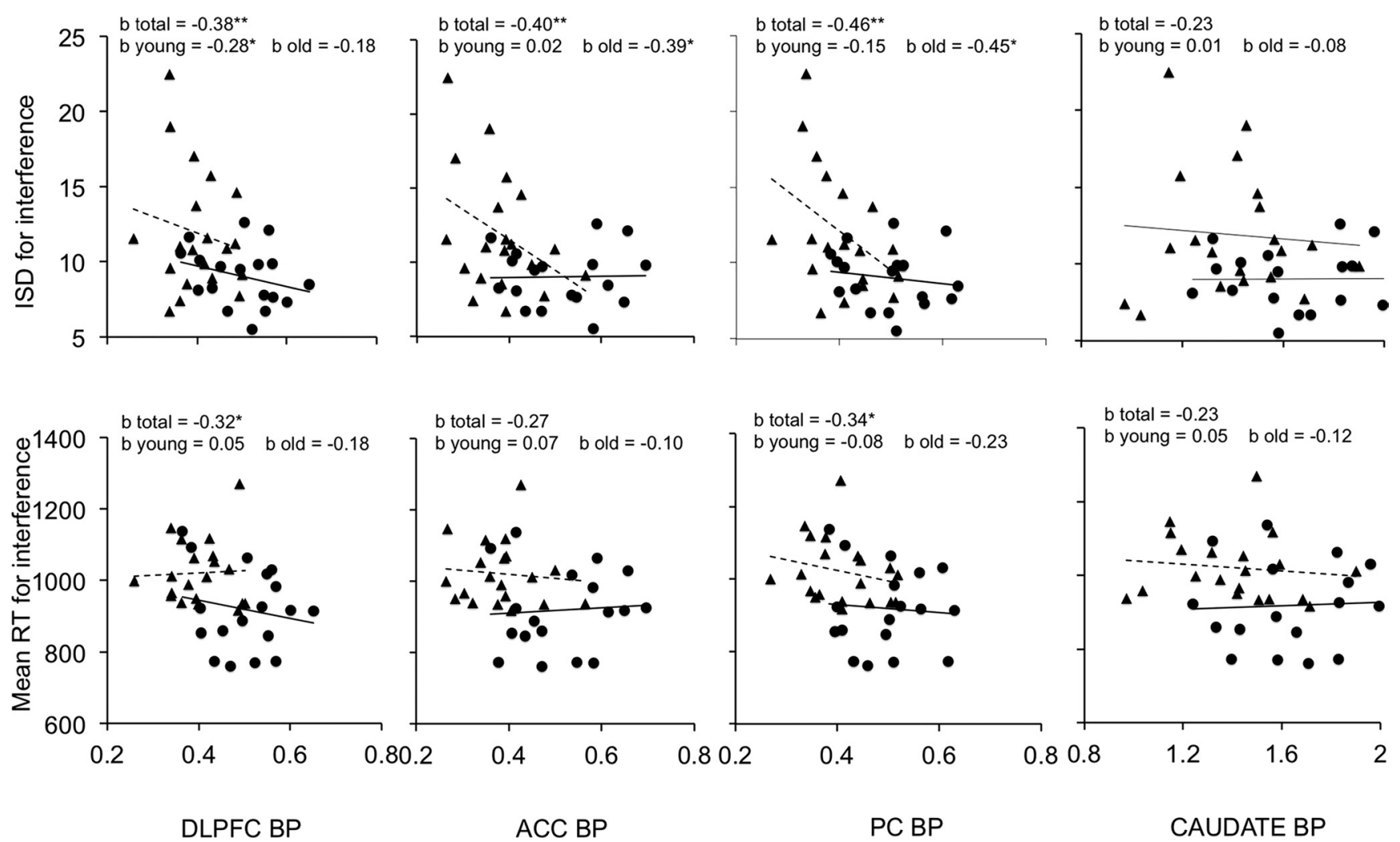

DLPFC BP

ACC BP

PC BP

CAUDATE BP

Figure 3. Scatterplots of the association of BP in DLPFC, ACC, PC, and caudate to variability (ISD) and mean RT for the MSIT interference condition. b total reports the standardized regression coefficient across all individuals. b young $(-)$ and b old $(\mathbf{\Delta})$ report coefficients for the respective age groups (with corresponding regression lines). ${ }^{*} p<0.05$, one-tailed; ${ }^{* *} p<0.01$, one-tailed.

DLPFC, -0.02 for ACC $(p>0.40)$, and 0.07 for PC $(p>0.20)$. In contrast, for variability (ISD) in MSIT-interference, the magnitude and significance of indirect effects was $0.01(p>0.45)$ for caudate, $0.11(p<0.10)$ for DLPFC, 0.13 for ACC $(p<0.10)$, and 0.17 for PC $(p<0.01)$.

The final step was to evaluate to what extent $\mathrm{DA}_{1}$ binding attenuated the direct effect of age on MSIT performance. Upon entering $\mathrm{DA}_{1}$ binding into the model, the initial link between age and mean RT latency ( $r=0.47)$ for the MSIT interference condition was partially mediated for DLPFC $(r=0.42, p<0.01$ one-tailed, or a $10.6 \%$ attenuation $)$ and $\mathrm{PC}(r=0.40, p<0.01$ one-tailed, a $14.9 \%$ reduction), with a modest attenuation observed for caudate $(r=0.46,2.1 \%)$, and no attenuation for ACC. In contrast, the magnitude of corresponding mediation of the age-ISD direct effect $(r=0.43)$ was comparatively larger, with partial mediation observed for DLPFC $(r=0.32, p<0.05$ 1-tailed; a $25.6 \%$ attenuation); full mediation of the agevariability effect was found upon controlling for $\mathrm{D}_{1}$ binding in ACC $(r=0.30, p>0.05$ one-tailed, a $30.2 \%$ attenuation of the initial age effect) and PC ( $r=0.26, p>0.10$ one-tailed, a $39.5 \%$ attenuation). Modest mediation was observed for caudate $(r=$ $0.42, p<0.01$ one-tailed, a $2.3 \%$ attenuation). Using Cohen and Cohen's (1983) procedure, inferential comparison of the agemean RT vs age-variability coefficients following mediation of $\mathrm{D}_{1}$ $\mathrm{BP}$ binding for each ROI yielded no significant differences. Notwithstanding, the differential patterns of mediation are notable, given that the zero-order associations between age and mean RT $(r=0.47)$ vs age and variability $(r=0.43)$ were remarkably similar, with the DA BP correlations uniformly higher for variability than for mean.

\section{Discussion}

This research provides novel evidence pertaining to the link among aging, DA activity, and IIV in RT during cognitive performance. In agreement with prior work (Suhara et al., 1991, Wang et al., 1998; Bäckman et al., 2010), old adults showed marked losses of $\mathrm{D}_{1} \mathrm{BP}$ in the key regions targeted (ACC, DLPFC, and PC) as well as in caudate while performing the MSIT, a task that taxes interference resolution. The magnitude of these losses was quite similar across regions, suggesting global decline of $\mathrm{D}_{1}$ receptors in aging.

The current data are consistent with prior observations demonstrating age-related increases in IIV during cognitive performance (MacDonald et al., 2006; 2009). Of key interest is the fact that the increase in IIV in old age was confined to interference trials in the MSIT; no such increases were observed for control trials, indicating that the executive demands of a cognitive task modulate the presence of age-related differences in IIV (West et al., 2002). Another interesting observation is that the differential effect of aging on IIV in the interference condition was not seen for mean RTs; the mean latency data revealed general age-related slowing that generalized across both experimental conditions. Finally, the degree of attenuation of the age-MSIT association, controlling for $\mathrm{D}_{1}$ binding in the CFP network, was greater for variability than for mean latency. The observed patterns suggest that age-related DA losses may have a greater bearing on variability than on mean latency in a task that taxes interference resolution.

Increased variability for the MSIT interference condition was linked to decrements in $\mathrm{D}_{1} \mathrm{BP}$ binding for regions in ACC, DLPFC, and PC; this relationship was not seen for $D_{1} B P$ in the 
caudate. The former regions are part of the CFP network that has been implicated in MSIT performance during interference in fMRI research (Bush et al., 2003; Bush and Shin, 2006). Critically, the fact that similar associations were observed between PETderived measures of $\mathrm{D}_{1} \mathrm{BP}$ and IIV is consistent with observations of a link between DA activity and the magnitude of the BOLD signal (Schott et al., 2008; Landau et al., 2009; Nyberg et al., 2009; Bäckman et al., 2011a,b). To substantiate this link, future multimodal imaging work should integrate PET assessment of DA functions with functional activation data during the MSIT.

Further, the fact that a DA-IIV link was found for the CFP network, but not for caudate, is notable in light of current theorizing on DA receptors and brain regions regarding their importance to different executive functions (Cools and D'Esposito, 2011). Specifically, several studies indicate a key role of extrastriatal DA receptors in stabilizing cognitive performance, whereas striatal receptors are more implicated in cognitive flexibility (Wang et al., 2004; Durstewitz and Seamans, 2008). The differential relationship of IIV to extrastriatal vs caudate DA receptors observed in this study is in agreement with these assertions.

The association between age and IIV in the interference condition was related to $\mathrm{D}_{1} \mathrm{BP}$ for regions within the CFP network. For each region, $>25 \%$ of the age-IIV association was accounted for by DA BP, underscoring the neuromodulatory impact that DA exerts on cognitive variability. In contrast, the association between age and mean RT was but modestly attenuated (14\% or less) upon covarying $\mathrm{D}_{1} \mathrm{BP}$ for the same regions. A likely source of the observed associations is that impaired dopaminergic neuromodulation results in increased neural noise. A decreased signal-to-noise ratio in task-relevant brain regions may give rise to more fluctuations and corresponding performance decrements at the behavioral level (Cohen and Servan-Schreiber, 1992; Li et al., 2001; MacDonald et al., 2009). Although it is intriguing that the aging-IIV association was markedly reduced in the presence of $D_{1} B P$, a word of caution is warranted. As the present findings are based on cross-sectional data, no causal claims can be made regarding how DA changes across the lifespan are linked to variability in cognitive function (Lindenberger et al., 2011; Raz and Lindenberger, 2011). Despite this limitation, ample evidence documents age-related decreases in DA functions in both human and animal research (Bäckman et al., 2006; 2010). Thus, changes in DA modulation may be considered among the biologically plausible mechanisms that contribute to increased variability in cognitive function in old age.

Overall, the current findings are consistent with the "correlative triad" among aging, DA, and cognitive performance (Bäckman et al., 2006; 2010), suggesting that DA losses are associated with age-related increases in performance variability. Such effects have previously been observed for striatal DA markers across various cognitive domains, including episodic memory and perceptual speed (Bäckman et al., 2000), as well as for working memory and verbal fluency (Erixon-Lindroth et al., 2005). The present data extend these observations by demonstrating equally strong effects regarding extrastriatal DA markers in the context of IIV across response latency trials. The data are consistent with: (1) the view that DA signaling may be particularly important under high executive demands; (2) the dopaminergic system playing a key role in coordinating activity patterns in distinct regions of the neocortex (Wichmann and DeLong, 1999; O'Reilly and Frank, 2006; Karlsson et al., 2009); and (3) a possible extension of the DA-BOLD link to the CFP network.

\section{References}

Abi-Dargham A, Simpson N, Kegeles L, Parsey R, Hwang DR, Anjilvel S, Zea-Ponce Y, Lombardo I, Van Heertum R, Mann JJ, Foged C, Halldin C, Laruelle M (1999) PET studies of binding competition between endogenous dopamine and the $\mathrm{D}_{1}$ radiotracer $\left[{ }^{11} \mathrm{C}\right] \mathrm{NNC}$. Synapse 32:93-109.

Abi-Dargham A, Mawlawi O, Lombardo I, Gil R, Martinez D, Huang Y, Hwang DR, Keilp J, Kochan L, Van Heertum R, Gorman JM, Laruelle M (2002) Prefrontal dopamine $D_{1}$ receptors and working memory in schizophrenia. J Neurosci 22:3708-3719.

Bäckman L, Ginovart N, Dixon RA, Wahlin TB, Wahlin A, Halldin C, Farde L (2000) Age-related cognitive deficits mediated by changes in the striatal dopamine system. Am J Psychiatry 157:635-637.

Bäckman L, Nyberg L, Lindenberger U, Li SC, Farde L (2006) The correlative triad among aging, dopamine, and cognition: current status and future prospects. Neurosci Biobehav Rev 30:791-807.

Bäckman L, Lindenberger U, Li SC, Nyberg L (2010) Linking cognitive aging to alterations in dopaminergic neurotransmitter functioning: recent data and future avenues. Neurosci Biobehav Rev 34:670-677.

Bäckman L, Nyberg L, Soveri A, Johansson J, Andersson M, Dahlin E, Neely AS, Virta J, Laine M, Rinne JO (2011a) Effects of working-memory training on striatal dopamine release. Science 333:718.

Bäckman L, Karlsson S, Fischer H, Karlsson P, Brehmer Y, Rieckmann A, MacDonald SW, Farde L, Nyberg L (2011b) Dopamine $\mathrm{D}_{1}$ receptors and age differences in brain activation during working memory. Neurobiol Aging 32:1849-1856.

Bunce D, Anstey KJ, Christensen H, Dear K, Wen W, Sachdev P (2007) White matter hyper intensities and within-person variability in community-dwelling adults aged 60 to 64 years. Neuropsychologia 45:2009-2015.

Bush G, Shin LM (2006) The multi-source interference task: an fMRI task that reliably activates the cingulo-frontal-parietal cognitive/attention network. Nat Protoc 1:308-313.

Bush G, Shin LM, Holmes J, Rosen BR, Vogt BA (2003) The multi-source interference task: Validation study with fMRI in individual subjects. Mol Psychiatry 8:60-70.

Cervenka S, Bäckman L, Cselényi Z, Halldin C, Farde L (2008) Associations between dopamine $\mathrm{D}_{2}$-receptor binding and cognitive performance indicate functional compartmentalization of the human striatum. Neuroimage 40:1287-1295.

Cervenka S, Varrone A, Fransén E, Halldin C, Farde L (2010) PET studies of $\mathrm{D}_{2}$-receptor binding in striatal and extrastriatal brain regions: biochemical support in vivo for separate dopaminergic systems in humans. Synapse 64:478-485.

Chou YH, Karlsson P, Halldin C, Olsson H, Farde L (1999) A PET study of $\mathrm{D}_{1}$-like dopamine receptor ligand binding during altered endogenous dopamine levels in the primate brain. Psychopharmacology 146:220-227.

Cohen J, Cohen P (1983) Applied multiple regression/correlation analysis for the behavioral sciences (Ed 2). Hillsdale, NJ: Erlbaum.

Cohen JD, Servan-Schreiber D (1992) Context, cortex, and dopamine: a connectionist approach to behavior and biology in schizophrenia. Psychol Rev 99:45-77.

Cools R, D'Esposito M (2011) Inverted-U-shaped dopamine actions on human working memory and cognitive control. Biol Psychiatry 69:e113-e125.

Durstewitz D, Seamans JK (2008) The dual-state theory of prefrontal cortex dopamine function with relevance to catechol-o-methyltransferase genotypes and schizophrenia. Biol Psychiatry 64:739-749.

Erixon-Lindroth N, Farde L, Wahlin TB, Sovago J, Halldin C, Bäckman L (2005) The role of the striatal dopamine transporter in cognitive aging. Psychiatry Res 138:1-12.

Hall H, Farde L, Sedvall G (1988) Human dopamine receptor subtypes-in vitro binding analysis using ${ }^{3} \mathrm{H}-\mathrm{SCH} 23390$ and ${ }^{3} \mathrm{H}$-raclopride. J Neural Transm 73:7-21.

Halldin C, Stone-Elander S, Farde L, Ehrin E, Fasth KJ, Långström B, Sedvall G (1986) Preparation of ${ }^{11}$ C-labelled SCH 23390 for the in vivo study of dopamine $\mathrm{D}_{1}$ receptors using positron emission tomography. Int J Rad Appl Instrum A 37:1039-1043.

Hultsch DF, MacDonald SW, Dixon RA (2002) Variability in reaction time performance of younger and older adults. J Gerontol B Psychol Sci Soc Sci 57:P101-P115.

Hultsch DF, Strauss E, Hunter MA, MacDonald SWS (2007) Intraindividual variability, cognition, and aging. In: The handbook of aging and 
cognition, Ed 2 (Craik FIM, Salthouse TA, eds), pp 491-556. New York: Psychology.

Innis RB, Cunningham VJ, Delforge J, Fujita M, Gjedde A, Gunn RN, Holden J, Houle S, Huang SC, Ichise M, Iida H, Ito H, Kimura Y, Koeppe RA, Knudsen GM, Knuuti J, Lammertsma AA, Laruelle M, Logan J, Maguire RP, et al. (2007) Consensus nomenclature for in vivo imaging of reversible binding radioligands. J Cereb Blood Flow Metab 27:1533-1539.

Karlsson S, Nyberg L, Karlsson P, Fischer H, Thilers P, MacDonald S, Brehmer Y, Rieckmann A, Halldin C, Farde L, Bäckman L (2009) Modulation of striatal dopamine $\mathrm{D}_{1}$ binding by cognitive processing. Neuroimage 48:398-404.

Kelly AM, Uddin LQ, Biswal BB, Castellanos FX, Milham MP (2008) Competition between functional brain networks mediates behavioral variability. Neuroimage 39:527-537.

Koepp MJ, Gunn RN, Lawrence AD, Cunningham VJ, Dagher A, Jones T, Brooks DJ, Bench CJ, Grasby PM (1998) Evidence for striatal dopamine release during a video game. Nature 393:266-268.

Lammertsma AA, Hume SP (1996) Simplified reference tissue model for PET studies. Neuroimage 4:153-158.

Landau SM, Lal R, O’Neil JP, Baker S, Jagust WJ (2009) Striatal dopamine and working memory. Cereb Cortex 19:445-454.

Li SC, Lindenberger U, Sikström S (2001) Aging cognition: from neuromodulation to representation. Trends Cogn Sci 5:479-486.

Lindenberger U, von Oertzen T, Ghisletta P, Hertzog C (2011) Crosssectional age variance extraction: what's change got to do with it? Psychol Aging 26:34-47.

Lövdén M, Li SC, Shing YL, Lindenberger U (2007) Within person trial-bytrial variability precedes and predicts cognitive decline in old and very old age: longitudinal data from the Berlin Aging Study. Neuropsychologia 45:2827-2838.

MacDonald SW, Nyberg L, Bäckman L (2006) Intra-individual variability in behavior: links to brain structure, neurotransmission and neuronal activity. Trends Neurosci 29:474-480.

MacDonald SW, Hultsch DF, Dixon RA (2008) Predicting impending death: Inconsistency in speed is a selective and early marker. Psychol Aging 23:595-607.

MacDonald SW, Li SC, Bäckman L (2009) Neural underpinnings of withinperson variability in cognitive functioning. Psychol Aging 24:792-808.

Meltzer CC, Leal JP, Mayberg HS, Wagner HN Jr, Frost JJ (1990) Correction of PET data for partial volume effects in human cerebral cortex by MR imaging. J Comput Assist Tomogr 14:561-570.

Nyberg L, Andersson M, Forsgren L, Jakobsson-Mo S, Larsson A, Marklund P, Nilsson LG, Riklund K, Bäckman L (2009) Striatal dopamine $D_{2}$ binding is related to frontal BOLD response during updating of long-term memory representations. Neuroimage 46:1194-1199.

O'Reilly RC, Frank MJ (2006) Making working memory work: A computational model of learning in the prefrontal cortex and basal ganglia. Neural Comput 18:283-328.

Ratcliff R, Thapar A, Gomez P, McKoon G (2004) A diffusion model analysis of the effects of aging in the lexical-decision task. Psychol Aging 19:278-289.

Raz N, Lindenberger U (2011) Only time will tell: cross-sectional studies offer no solution to the age-brain-cognition triangle: comment on Salthouse (2011) Psychol Bull 137:790-795.

Roland PE, Graufelds CJ, Wåhlin J, Ingelman L, Andersson M, Ledberg A, Pedersen J, Åkerman S, Dabringhaus A, Zilles K (1994) Human brain atlas for high resolution functional and anatomical mapping. Hum Brain Mapp 1:173-184.

Schott BH, Minuzzi L, Krebs RM, Elmenhorst D, Lang M, Winz OH, Seidenbecher CI, Coenen HH, Heinze HJ, Zilles K, Düzel E, Bauer A (2008) Mesolimbic functional magnetic resonance imaging activations during reward anticipation correlate with reward-related ventral striatal dopamine release. J Neurosci 28:14311-14319.

Spieler DH, Balota DA, Faust ME (2000) Levels of selective attention revealed through analyses of response time distributions. J Exp Psychol Hum Percept Perform 26:506-526.

Strauss E, MacDonald SW, Hunter M, Moll A, Hultsch DF (2002) Intraindividual variability in cognitive performance in three groups of adults: cross-domain links to physical status and self-perceived affect and beliefs. J Int Neuropsychol Soc 8:893-906.

Suhara T, Fukuda H, Inoue O, Itoh T, Suzuki K, Yamasaki T, Tateno Y (1991) Age-related-changes in human $D_{1}$-dopamine receptors measured by positron emission tomography. Psychopharmacology 103:41-45.

Tamraz JC, Comair YG (2005) Atlas of regional anatomy of the brain using MRI: functional correlates, pp115-137. Berlin: Springer.

Wang M, Vijayraghavan S, Goldman-Rakic PS (2004) Selective D2 receptor actions on the functional circuitry of working memory. Science 303:853856.

Wang Y, Chan GL, Holden JE, Dobko T, Mak E, Schulzer M, Huser JM, Snow BJ, Ruth TJ, Calne DB, Stoessl AJ (1998) Age-dependent decline of dopamine $D_{1}$ receptors in human brain: a PET study. Synapse 30:56-61.

West R, Murphy KJ, Armilio ML, Craik FI, Stuss DT (2002) Lapses of intention and performance variability reveal age-related increases in fluctuations of executive control. Brain Cogn 49:402-419.

Wichmann T, DeLong MR (1999) Oscillations in the basal ganglia. Nature 400:621-622. 